\title{
La (des) integración del diferente en la sociedad peruana
}

\section{The (Dis) Integration of the Different in the Peruvian Societ}

Cosme Batallas Lara*

http://dx.doi.org/10.21503/lex.v16i22.1660

* Lingüista y diplomático, egresado de la maestría de Relaciones Internacionales y Diplomacia del Instituto de Altos Estudios Nacionales, Ecuador. Maestrante de la Escuela de Gobierno y Políticas Públicas de la Pontificia Universidad Católica del Perú. Correo electrónico: cosmebatlar@gmail.com

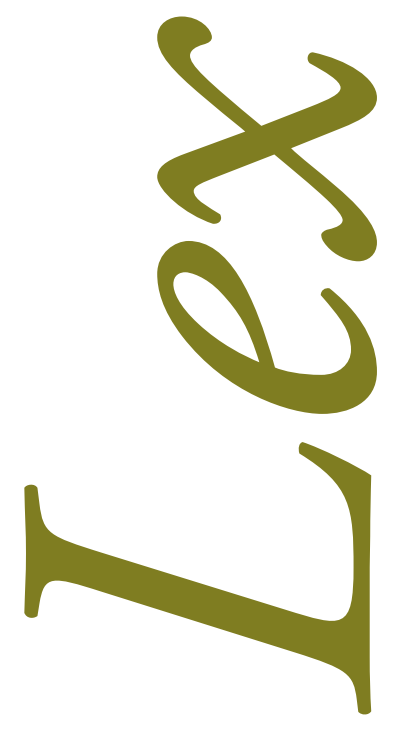




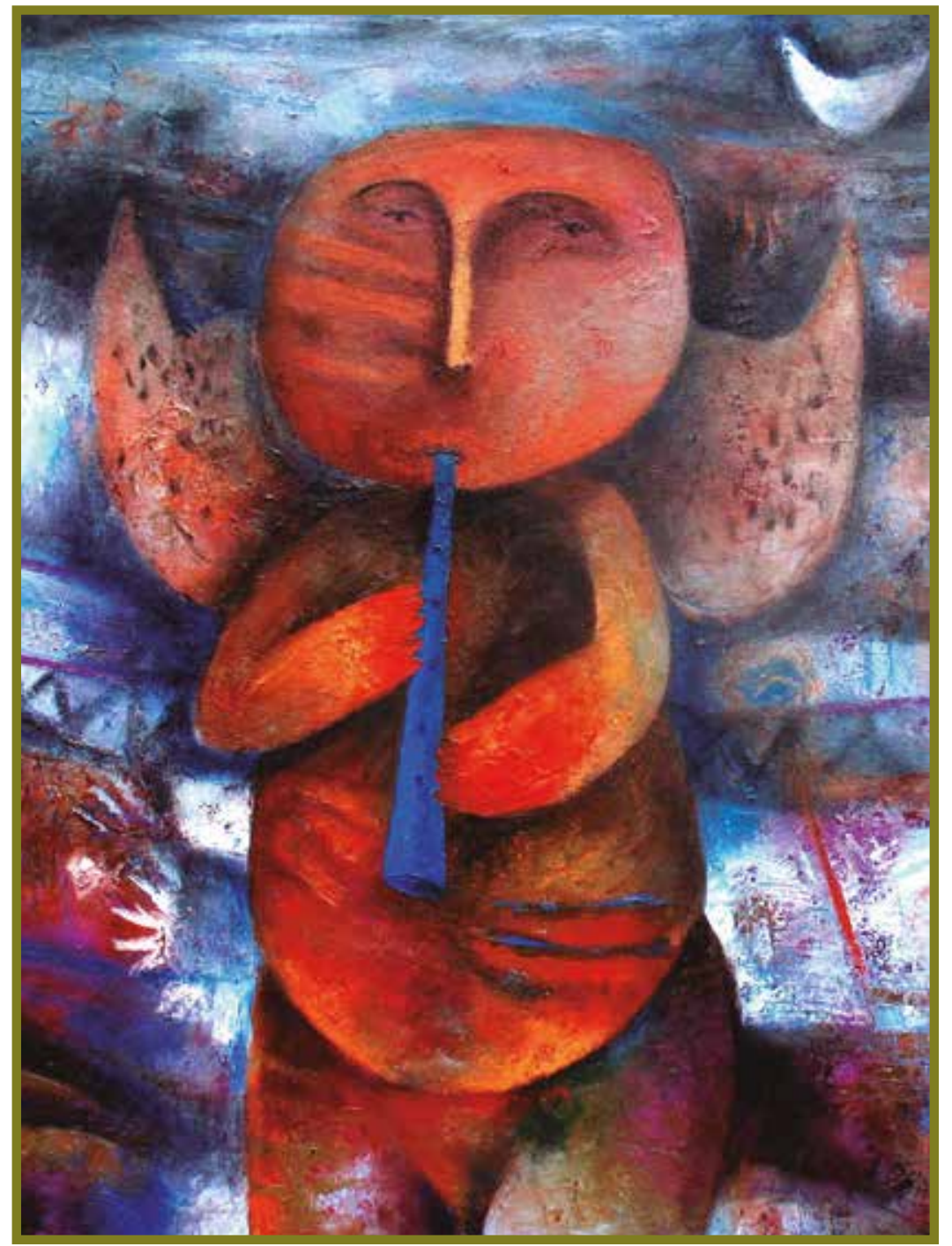

Canto a la Paz. Pintura. Juan Carlos Nananake. 


\section{RESUMEN}

La cotidianidad de la sociedad peruana da cuenta de las profundas brechas socioeconómicos presentes en una estructura estratificada en forma piramidal. Desigualdades que deviene en tratos degradantes y discriminatorios, vulnerando flagrantemente los derechos de las y los peruanos considerados diferentes. En el Perú conviven aproximadamente cincuenta y cinco pueblos y nacionalidades originarias, distribuidas entre Sierra, Costa y Amazonía. Cada una poseedora de un bagaje cultural, cosmológico y sociológico de enorme valía, elementos sobre los cuales han construido su propia identidad. Particularidades que paradójicamente han repercutido negativamente en su proceso de integración en la esfera social reinante la capital de todos los peruanos. En este contexto, el presente trabajo visibiliza, desde el ámbito social, cultural y ético, la cultura urbana del ciudadano peruano radicado en Lima y su relacionamiento con el diferente, con el peruano nacido fuera de Lima. De igual manera, se evidenciarán los efectos abrasivos de esta dispar simbiosis, la cual ha causado y causa un efecto de aculturación en el ciudadano diferente, quien en aras de ganarse un espacio en la ciudad intenta mimetizarse con el entorno citadino, a costo incluso de ocultar o maquillar su origen indígena, despojándose de aquello que le hace diferente, - su propia identidad-.

Palabras clave: diferente, (des)integración, (in) justicia, discriminación, indígena.

\section{ABSTRACT}

The daily life of Peruvian Society accounts for the profound socio-economic gaps present in a pyramid-stratified structure. Inequalities manifested in degrading and discriminatory treatment, flagrantly violating the rights of Peruvians considered "different". In Peru, approximately fifty-five native peoples and nationalities coexist, distributed between the Highlands, the Coast and the Amazon. Each one a possessor of a cultural, cosmological and sociological baggage of enormous value, elements in which they have built their own identity. Peculiarities that paradoxically have negatively affected the process of integration in the social sphere reigning in the capital of all Peruvians. In this context, the present essay, visualizes from the social, the cultural and the ethical spheres, the urban culture of the Peruvian citizen based in Lima and its relationship with the different one, with the Peruvian born outside of Lima. Similarly, the abrasive effects of this disparate symbiosis will be evident, which has caused and still causes acculturation effects on the different citizen, who, to gain a space in the city, try to mimic the urban environment, at the cost of even to hide, hinder or masquerade their indigenous origin, shedding off what makes them different - their own identity.

Key words: different, (dis)integration, (in) justice, discrimination, indigenous. 


\section{LA (DES) INTEGRACIÓN DEL DIFERENTE EN LA SOCIEDAD PERUANA}

La Feria Exposición Ruraq Maki (hecho a mano) es un espacio de exhibición y venta de artesanías provenientes de diversas regiones del Perú. Congrega a destacadas organizaciones de artistas y artesanos que han dedicado gran parte de su vida a la creación y transmisión del arte tradicional peruano. Este (re)encuentro artístico artesanal cuenta con el auspicio del Ministerio de Cultura y usualmente se desarrolla una vez al año. Tuve la oportunidad de asistir a la emisión del año 2017, y la primera impresión que excitó mis sentidos fue el sentirme imbuido en aquella marea de formas, colores y texturas, todas nuevas para mí y completamente diferentes a las impuestas y expuestas por los diseñadores de moda en los elegantes escaparates de los malls de la ciudad, Creo que justamente la magia está en eso, en la diferencia, en la originalidad y la hermosura de la simplicidad.

Recorría sin fatiga toda la extensa área de la exhibición, en un momento me detuve y mis ojos llevaron mi mirada justo detrás de las estanterías sobre los que se exhibían los distintos trabajos. En ese momento mi atención se volcó sobre los artesanos, su apariencia cobriza, sincera y transparente. Me fijé en cada detalle de su indumentaria, en cada combinación de color, en los materiales utilizados, en sus diseños únicos. Le pregunté a una de ellas de dónde era, me contestó que había nacido en Juliaca, pero desde hace seis años vivía en Lima. "Yo también vivo en Lima", le contesté, y sin embargo nunca he visto a nadie en esta ciudad utilizando un vestuario parecido al suyo. "Es que si yo salgo vestida así, no me dejan ni subir a los buses", respondió.

Mirando más allá de lo evidente, descubrí que lo que hacía realmente único a ase espacio era su gente, su vestimenta, sus idiomas originarios, su apariencia. Pero la gente no estaba a la venta, ninguno de los visitantes querría un indio shipibo, un kechwa o un ashaninka sentado en la sala de su casa. Mucho es llevarlos como parte de una selfie en sus teléfonos inteligentes.

"Si salgo vestida así, no me dejan ni subir a los buses"; no solo a los buses, debería añadirse: tampoco la dejarán ingresar a un trabajo que a más de digno le permita pagar una educación de calidad para ella y sus hijos. Sin una buena educación, tampoco le permitirán subirse a un 
buen empleo, y sin un buen empleo nunca podrá salir de la condición de pobreza degradante que la rodea, y su descendencia tampoco.

Si sale vestida así, la pequeña artesana de Juliaca jamás será integrada a la sociedad limeńa, será confinada a merodear los opulentos lares donde habitan los peruanos de Lima, y le será permitido acercarse únicamente para servirles y hacerles la vida más cómoda, más placentera, más integra.

Si la pequeña artesana de Juliaca sale vestida así, no le permitirán sońar, no podrá aspirar a mejorar su calidad de vida, no podrá ser integrada a la sociedad limeña, ni siquiera le será permitido subirse en un bus de servicio urbano. Si sale vestida así será desintegrada, en toda la dimensión de la palabra.

Como sociedad, nos hemos encargado de desintegrar al diferente, de neutralizarlo, de acallarlo, de aislarlo. Hanna Arendt ${ }^{1}$ menciona que la acción, a diferencia de la fabricación, nunca es posible en aislamiento. Estar aislado o desintegrado es lo mismo que carecer de capacidad de actuar, y aun si el desintegrado hablara, se necesita un espacio para que sus ideas sean escuchadas. La acción y el discurso, seńala la autora, necesitan la presencia de la naturaleza para su material y un mundo en el cual colocar el producto acabado. La fabricación está rodeada y en contacto con el mundo; las acciones y el discurso lo están con la trama de los actos y palabras de otros hombres.

Como podemos apreciar, Hannah Arendt sostiene que un discurso sin interlocutor carece de valor. Tener la capacidad de expresar las ideas pero no el valor (entiéndase valor como las cualidades que hacen que una persona sea apreciada) de llamar la atención de los próximos es igual de injusto que hablarle al vacío. La (in)capacidad de ignorar la presencia discreta del diferente es una de las formas más lacerantes de injusticia.

Ignorar su presencia, sus ideas, sus capacidades es una forma de represión. Dicho de otro modo es violentar lo que llama Amartya Zen² sus libertades sustanciales.

En palabras de Zen, citadas por Martha Nussbaum, ${ }^{3}$ la capacidad de una persona hace referencia a las combinaciones alternativas de funcionamiento que resulta factible alcanzar. La capacidad viene a ser, por lo tanto —enfatiza Nussbaum—, una especie de libertad. Dicho de otro modo, no son simples habilidades residentes en el interior de una persona, sino que incluyen también las libertades o las oportunidades creadas por la combinación entre esas facultades personales y el entorno político, social y económico.

\footnotetext{
Hanna Arendt, La condición humana (Chicago: The University of Chicago Press, 1996), 176-192.

Amartya Zen, La libertad individual como compromiso social (Ediciones Abya-Yala, 2000), 52.

3 Martha Nussbaum, "Una mujer en busca de justica”, en Creando capacidades (Madrid: Artes Gráficas Huertas, 2012), $19-64$.
} 
Aplicando esta definición a la realidad de la artesana de Juliaca, sus capacidades combinadas son la totalidad de oportunidades de las cuales dispondría para elegir y para actuar en su situación política, social y económica concreta.

Las dificultades de identificar a las víctimas de la injusticia y las muchas formas en que todos aprendemos a convivir con las secuelas que esta causa en los demás tienden a ser ignoradas. ¿Por qué no pensar en aquellas experiencias que llamamos injustas como fenómenos independientes por derecho propio? El sentido común y la historia nos dicen que son experiencias cotidianas y que reclaman nuestra atención inmediata. La mayoría de nosotros hemos exclamado muchas veces que eso es injusto. Afortunadamente, la teoría política, que habita a medio camino entre la historia y la ética, parece ser la herramienta ideal para hacer algo al respecto. Después de todo, la (in)justicia no es una noción políticamente (in)significante y la variedad y frecuencia de actos de injustica invitan a un estilo de pensamiento menos abstracto que la ética, pero más analítico que la historia. Cuando menos, se puede acortar la distancia entre teoría y práctica cuando uno mira numerosas injusticias que cuando solo atiende a la consideración de lo (in)debido o (in)justo. ${ }^{4}$

Pese a que las secuelas de la injusticia son fácilmente cuantificables, al parecer no sería su víctima solo el que la recibe. El ciclo de la injusticia va en doble sentido. Dentro de esa dualidad, victimiza también a quien la profiere. A decir de Judith Shklar, la persona injusta, antes que nada, puede ser injusta consigo misma, infligiéndose heridas sobre su propia alma. Esta fue la perspectiva de Platón, que pensaba que las personas injustas realmente no saben lo que hacen, no actúan voluntariamente y están tan mal orientadas, que en lugar de ser juzgadas merecen la conmiseración. Estas personas sufren por sus desordenadas psiques y están tan atormentadas por el tironeo de deseos e ira reprimidas que son incapaces de controlar. Irracionalidad, insolencia, deseos irrefrenables, agresividad sin límites, son todas estas patologías, a su propio modo, enfermedades psíquicas que nos hacen ser injustos. ${ }^{5}$

"Es que si yo salgo vestida así, no me dejan ni subir a los buses". Si acaso la artesana de Juliaca lograra abordar el bus vestida así, ¿habrá alguien que la mire?, ¿que le dirija un saludo o le ceda un asiento? La respuesta es obvia, nadie la verá, será invisibilizada debido a su atuendo y apariencia diferentes, debido a su origen y nivel socioeconómico diferentes. Paradójico pero cierto; aquello que la hace diferente, que la resalta en medio del tumulto, la convierte en un ser invisible, inexistente, ausente. La artesana de Juliaca está sola en medio de tanta gente, perdida entre decenas de miradas, incapaz de crear, de expresar, o de hacer. A pesar de todo su potencial humano, la artesana de Juliaca es incapaz de ser.

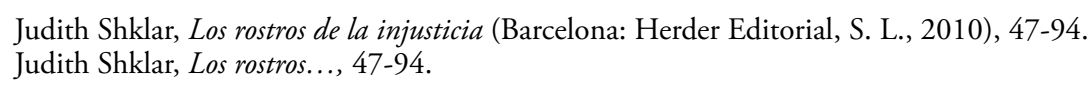


La convicción de que lo más grande que puede lograr el hombre es su propia aparición y realización no es cosa natural. Contra esta convicción se levanta la del Homo faber al considerar que los productos o la creación del hombre pueden ser más y no solo más duraderos que el propio hombre, y también la firme creencia de que la vida es el más elevado de todos los bienes, ya que la vida constituye el espacio que debiera permitirle al hombre trascender y desarrollar toda su capacidad creadora. Arendt ${ }^{6}$ menciona que es un elemento indispensable del orgullo humano la creencia de que quien es alguien trasciende en grandeza e importancia a todo lo que el hombre puede hacer y producir.

En el Perú, desde la mirada cultural criolla y en la vida cotidiana, tendencialmente, pareciera que ya no existe lo indígena y que hoy solo se trata de campesinos o de excampesinos desarraigados, cholificados o de minorías indígenas tradicionales, encapsuladas geográficamente y dispuestas únicamente a la exhibición etnoturística, y que, entonces, la especificidad de sus expresiones simbólicas, creencias, sensibilidades, valores, lenguas ya no pertenecen al ámbito cultural de lo indígena-reivindicativo, o peor aún: que tales expresiones están ya casi diluidas. Digo pareciera, porque no es así. Los indígenas, y sin pretender alguna romántica idealización, están culturalmente vivos con (y desde) su música, su laboriosidad, su reciprocidad, sus redes de parentesco, su curanderismo, sus fiestas, su gastronomía, su religiosidad semimágica y su concepción del tiempo; hablando sus propias lenguas, apropiándose y resignificando, a su vez, todo lo que les sea funcional de las estructuras sociales y culturales hegemónicas. Y eso, estableciendo estrategias desde las cuales, y según sus contextos e interlocutores o expectativas, inventándose, además, tradiciones, o sobredimensionándolas en función a tales expectativas. Pero, también, asumiéndose como peruanos y ciudadanos peruanos, reivindicando sus especificidades simbólicas, pero, asimismo, reivindicando la igualdad ciudadana. También reivindicando muchas veces una suerte de ciudadanía étnica. Es decir, reivindicando la diferencia sin negar la igualdad ciudadana. Al contrario, buscando, paralelamente, afirmarla. ${ }^{7}$

Desde la óptica etnocéntrica e ideológica criolla, relacionada con la creencia de superioridad en el país, desde los inicios del siglo XX, a los indígenas se les negó el derecho a su individualidad y a su autonomía cultural. Según Molinari ${ }^{8}$, se les percibió bajo tres perspectivas que de alguna manera han influido, y con cierta intensidad, en la construcción de esas miradas criollas desintegradoras, desde las cuales y en la vida cotidiana, se tiende a invisibilizar o a negar al mundo cultural indígena de su también merecido derecho la ciudadanía peruana. He ahí, precisamente, la construcción paulatina de formas de negación con el Estado y con el logro de reconocimientos complejos. Las expectativas citadas por Tirso Molinari son las siguientes:

Hanna Arendt, La condición ..., 176-192

Tirso Molinari, "Sobre la invisibilización y las representaciones de lo indígena en el Perú", Revista de Investigaciones Sociales de la Universidad Nacional Mayor de San Marcos, n. ${ }^{\circ} 20$ (2018), acceso el 14 de julio de 2018, http://revistasinvestigacion.unmsm.edu.pe 
1. Desde la expansión de la educación pública. Así, en la "república aristocrática”, aparece el ideal liberal de la integración ciudadana de la población indígena, bajo una pragmática expansión educativa pública y con la castellanización compulsiva. Fue esa, entonces, la base para la pendiente tarea de la "integración nacional", derivada de aquella perspectiva liberal.

2. Desde el mestizaje, como proyecto de "unificación e integración nacional" y de "peruanidad", con el cual el impacto cultural-hispánico y el catolicismo se constituyen en el eje de aquella ideal integración criollo-indígena, entendida, a su vez, desde la hegemonía cultural criolla-católica, tal como lo concebían el propio Riva Agüero y sobre todo Víctor Andrés Belaunde.

3. Desde un singular racismo, pero nutrido ya de "justificaciones" biologicistas y positivistas, que reforzaban el más o menos espontáneo e histórico etnocentrismo y racismo criollo-hegemónico. Desde este enfoque es que se aboga por la inmigración de población europea, dado el explícito desprecio frente a la población indígena, pero también frente a la población de origen africano y asiático. Bajo ese etnocentrismo criollo, mediante el cual se descalificaba la autonomía cultural de la población indígena, surge aquel proyecto "integrador” pero, a su vez, muy cargado de violencia simbólica, con lo cual la ideología del mestizaje aparece como una suerte de coartada para validar ese hegemonismo criollo. ${ }^{8}$

El proceso de aniquilación y desintegración cultural infligido al diferente se encuentra anclado en el ideario del supuesto superior, de forma tal que no es capaz de discernir entre lo justo y lo injusto, entre lo correcto y lo incorrecto. En la mente colectiva del "superior", lo diferente no es real y todo el atropello del que el diferente es objeto simplemente no existe.

El aniquilador de identidad no cree estar vulnerando los derechos humanos, pues considera que los depositarios de aquella vulneración no son dignos o no merecen o simplemente no necesitan un trato digno. Pues esas cosas no se las están haciendo a congéneres humanos, sino a seres diferentes, a personas inferiores, a peruanos de Juliaca. No están siendo inhumanos, sino que diferencian entre verdaderos humanos y pseudohumanos. ${ }^{9}$

Cuando la artesana de Juliaca sale vestida de Juliaqueña, no merece la mirada de nadie, su presencia a nadie importa, su vida no significa nada, no es limeńa, y por lo tanto no existe. No merece existir porque al fin y al cabo es diferente. Quienes la rodean, según su concepción de lo (in)justo, no le están negado el derecho de existir a nadie, no están discriminando a nadie y tampoco están desintegrando a nadie.

La invisibilización del distinto no es exclusividad del Estado peruano, así como los indígenas no son las únicas víctimas de esta (a)normalidad. Para la mayoría de los blancos, hasta

Tirso Molinari, "Sobre la invisibilización y las Representaciones de lo indígena ...

9 Richard Rorty, Verdad y progreso (Barcelona: Ediciones Paidós Ibérica S. A., 1994), 221-236. 
hace bien poco, los negros no contaban dentro de sus estadisticas. Para la mayoría de los cristianos, más o menos hasta el siglo XVII, los paganos tampoco contaban. Para los nazis, no contaban los judíos. Para la mayor parte de los varones en los países con una renta media anual inferior, la mayoría de las mujeres siguen aún sin contar. ${ }^{10}$

El (re)conocer al distinto, valorar su capacidad, respetar su presencia es un acto que resalta la dignidad humana. De acuerdo a Martha Nussbaum, ${ }^{10}$ la dignidad es un elemento de la teoría, pero todos los conceptos empleados en esta se entienden como elementos interconectados entre sí, y que, como tales, se explican y se esclarecen mutuamente.

En el caso de la dignidad, la noción de respeto viene a ser un componente particularmente importante en ella, y son los principios políticos los que esclarecen el significado que damos a la dignidad humana. Pero la idea básica es que ciertas condiciones de vida facilitan a las personas una vida que es merecedora de la dignidad humana que ellas poseen, mientras que otras condiciones no lo hacen. En estas últimas circunstancias, las personas conservan dignidad pero esta funciona más como un pagaré cuyos plazos aún no han sido abonados. Tal como Martin Luther King Jr. dijo a propósito de las promesas inherentes a los ideales nacionales, la dignidad puede ser como "un cheque que nos han devuelto con una notificación de fondos insuficientes"11

Aunque la dignidad es una idea poco precisa que hay que dotar de contenido situándola en una red de nociones relacionadas, tiene un impacto diferencial. Muchas son las formas en las que se pueden negar las aspiraciones de dignidad humana, pero todas ellas son resumibles en dos que se corresponden precisamente con los ámbitos asociados a las capacidades intrínsecas de los seres humanos. Así, por un lado las condiciones sociales, políticas, familiares y económicas pueden impedir que las personas opten por funcionar conforme a una capacidad interna y desarrollada: este es un tipo de frustración comparable al encarcelamiento. Pero, por otro lado, las condiciones negativas pueden penetrar más a fondo en las personas atrofiando o deformando el desarrollo de sus capacidades internas; en ambos casos, prevalece la dignidad humana básica: la persona diferente sigue siendo merecedora de igual respeto que las demás. En el segundo de ellos, sin embargo, se ha vulnerado más profundamente esa dignidad. ${ }^{12}$

Frente a todos esos discursos, miradas y actitudes criollo-céntricas, que aún prevalecen en el Perú, desde las cuales se percibe culturalmente al indígena como el otro, el diferente, el inferior, surge la explicación de Kant, la cual resulta más que acertada para aquellos que de alguna manera inferiorizan a las multitudes oprimidas, social y culturalmente, a esas multitudes oprimidas que resultaban ser, en buena medida, indígenas.

10 Martha Nussbaum, "Una mujer en busca de ..., 19-64.

11 Martha Nussbaum, "Una mujer en busca de..., 19-64. 
La explicación de Kant, citado por Rorty ${ }^{12}$ a propósito de la desintegración del diferente menciona: "debes extender a todos los bípedos implumes el respeto que sientes por las personas que son como tú". Esa es una propuesta excelente, una buena forma para secularizar la doctrina cristina de la hermandad entre los hombres. Para hacer que los blancos tengan más consideración hacia los negros, los varones hacia las mujeres, los católicos hacia los cristianos y viceversa, los heterosexuales hacia los homosexuales, para contribuir a que nuestra especie quede viculada en una "comunidad planetaria", dominada por la cultura de los derechos humanos, no sirve absolutamente de nada lo mencionado por Kant: "Observen lo que tienen en común vuestra humanidad, es más importante que todas las triviales diferencias".

La justicia, que no es más ni menos que la dignidad, tiene como objetivo propagar la idea de un acuerdo equitativo a la propia estructura básica. Aquí surge una dificultad considerable para cualquier concepción política de la justicia que usa la idea de contrato. Sea o no social dicho contrato, se debe establecer un punto de vista desde el que se pueda alcanzar un acuerdo equitativo entre personas libres e iguales. ${ }^{13}$

Los derechos de todas y todos los peruanos son valuartes que deben ser impartidos equitativamente (no igualmente) entre todos. Los dos primeros artículos de la Constitución Política del Perú deberían consagrar la vigencia de la obligación que tiene el Estado de garantizar sine qua non su aplicación en toda población.

Artículo $1^{\circ}$.- La defensa de la persona humana y el respeto de su dignidad son el fin supremo de la sociedad y del Estado.

Artículo $2^{\circ}$.- Toda persona tiene derecho:

1. A la vida, a su identidad, a su integridad moral, psíquica y física y a su libre desarrollo y bienestar. El concebido es sujeto de derecho en todo cuanto le favorece.

2. A la igualdad ante la ley. Nadie debe ser discriminado por motivo de origen, raza, sexo, idioma, religión, opinión, condición económica o de cualquiera otra índole.

(Constitución Política del Perú, 1993)

Sin embargo, las pretenciones individualistas, egoístas y ambiciosas, de aquellos que viendo no quieren ver la igualdad en la diferencia, tergiversan la implementación de tal mandato. A la artesana de Juliaca se le ha privado de su identidad, ha sido desintegrada de la sociedad limeña, se le ha arrebatado su derecho al desarrollo y al bienestar; en definitiva, a la artesana de Juliaca se le ha atrofiado su derecho de ser. Frente a tal entuerto, Saúl Velasco Cruz ${ }^{14}$ propone tres alternativas de remediación.

12 Richard Rorty, Verdad y...

13 John Rawls, La justicia como equidad, una refomulación (Barcelona: Paidós, 2000), 24-63.

14 Saul Velasco, "El racismo y las tres formas básicas de combatirlo", Cultura y representaciones sociales, n. 3 (2007), acceso el 11 de julio de 2018, http://www.scielo.org.mx 


\section{El principio de la tolerancia}

A través de la historia humana, ha sido prácticamente una regla sine qua non atribuir al recurso de la tolerancia los argumentos no solo para permitir la libre competencia de ideas, puntos de vista diversos y posiciones políticas distintas, sino también para evitar la exclusión, discriminación y xenofobia fundadas en el racismo.

Muchos son los escritos de teoría y filosofía política que apelan al sentido normativo de la tolerancia y prescriben su observancia. Y en momentos de creciente pluralismo étnico, religioso, moral, etc., en los cuales la convivencia se torna conflictiva, las más distintas disciplinas sociales prescriben la tolerancia como recurso para garantizar la convivencia pacífica. Más aún, muchos personajes que intervienen en la confección de las políticas de instituciones como la ONU o la UNESCO se encargan de difundir y hacer pública las virtudes de la tolerancia. ${ }^{15}$

\section{Políticas contra la discriminación}

A diferencia de la alternativa que prescribe de manera general observar la tolerancia como forma de vida en circunstancias de creciente pluralidad, la propuesta legal promueve el establecimiento o la creación de políticas contra la discriminación y el racismo. Esta modalidad, hay que decirlo, es una alternativa derivada de la anterior que reconoce la legitimidad de la tolerancia para enfrentar al racismo, pero que a diferencia de aquella plantea, mediante la ley, un elemento disuasivo de la exclusión fundada en la discriminación racial.

Los sustentos legales de esta fórmula quizá haya que ubicarlos en la ya lejana Declaración de los Derechos del Hombre y el Ciudadano, de 1789. Pero sin duda, la referencia obligada es la Declaración Universal de los Derechos Humanos, de 1948, pues en su marco se formó la iniciativa que habría de dar origen a la Convención Internacional sobre la Eliminación de todas las Formas de Discriminación Racial, aprobada por las Naciones Unidas en $1965 .{ }^{15}$

\section{La alternativa educativa contra la discriminación racial}

En contraste con las dos modalidades previas, la tercera forma de combatir la discriminación racial no se ocupa directamente de contrarrestarla apelando a la tolerancia (en su definición filosófica general), ni de inhibirla mediante la ley, sino más bien de prevenirla y en todo caso de neutralizarla. Su esfera de acción descansa en el área de competencia de la educación. Difícilmente puede ponerse en duda la capacidad de la educación para engendrar las virtudes ciudadanas, pero no solo para engendrarlas sino también para cultivarlas y para fomentarlas en la conducta y en los hábitos de los ciudadanos que reciben su influjo. Es verdad que,

15 Saúl Velasco, "El racismo y las tres formas básicas de combatirlo", Cultura y representaciones sociales, n. 3 (2007), acceso el 11 de julio de 2018, http://www.scielo.org.mx 
contrario a lo que por mucho tiempo se ha creído, la educación no puede resolverlo todo, pero sí es importante el papel preventivo que puede ejercer con respecto a la discriminación racial y la intolerancia. En materia de virtudes ciudadanas, se ha dicho que la educación no es solo un asunto de la escuela, sino también de otras instituciones sociales. Por ejemplo, para algunos, el mercado (medios de comunicación, publicidad, propaganda) desempeña un papel educativo importantísimo. ${ }^{16}$

Debemos entonces, como sociedad peruana, propiciar, desde nuestra propia individualidad, las condiciones más óptimas para que la artesana de Juliaca, al igual que sus hermanas y hermanos de los Andes, el pescador de la Costa, el agricultor de la Amazonía, o el agroganadero de Chincha se sientan orgullosos de su identidad, de sus haceres y saberes, de su atuendo diferente; que se afiancen heroicos en sus capacidades fortalecidas y con su dignidad revitalizada. Que la artesana de Juliaca haga efectivo el pagaré que garantizará su libre acceso a todo aquello que contribuya al florecimiento de sus capacidades y se sienta integrada por derecho propio en la sociedad a la que pertenecemos todas y todos, la peruana.

Que Lima, y todo este Perú diverso se enriquezcan con el orgullo de contar con baluartes que con su diferencia embellecen su entorno; después de todo, la verdadera riqueza se encuentra en la diversidad, y la grandeza de una patria se evidencia en la aplicación de los derechos en igualdad.

Bajo el abrigo de estas condiciones, la artesana Juliaca se sentirá más ella y no tendrá necesidad de ataviarse con ropajes que no le pertenecen, que ocultan su diferencia para hacerla sentir igual. Condiciones de equidad y de igualdad fomentan la dignidad, el autoestima y patriotismo, valores imperecederos en la construcción de una sociedad más justa, más fraterna y más humana.

\section{REFERENCIAS}

- Arendt, Hanna. La condición humana. Chicago: The University of Chicago Press, 1996.

- Molinari, Tirso. "Sobre la invisibilización y las representaciones de lo indígena en el Perú". Revista de Investigaciones Sociales de la Universidad Nacional Mayor de San Marcos, n. ${ }^{\circ} 20$ (2008): 217-227. Acceso el 14 de julio de 2018. http://revistasinvestigacion.unmsm.edu. pe

- Nussbaum, Martha. "Una mujer en busca de justica". En Creando capacidades, 19-64. Madrid: Artes Gráficas Huertas, 2012. 
- Rawls, John. La justicia como equidad, una refomulación. Barcelona: Paidós, 2000.

- Rorty, Richard. Verdad y progreso. Barcelona: Ediciones Paidós Ibérica S. A., 1994.

- Shklar, Judith. Los rostros de la injusticia. Barcelona: Herder Editorial, S.L., 2010.

- Velasco, Saúl. "El racismo y las tres formas básicas de combatirlo". Cultura y representaciones sociales, $\mathrm{n}^{\circ}{ }^{\circ} 3$ (2007). Acceso el 11 de julio de 2018. http://www.scielo.org.mx

- Zen, Amartya. La libertad individual como compromiso social. Ediciones Abya-Yala, 2000.

RECIBIDO: 07/08/2018

APROBADO: 23/10/2018 


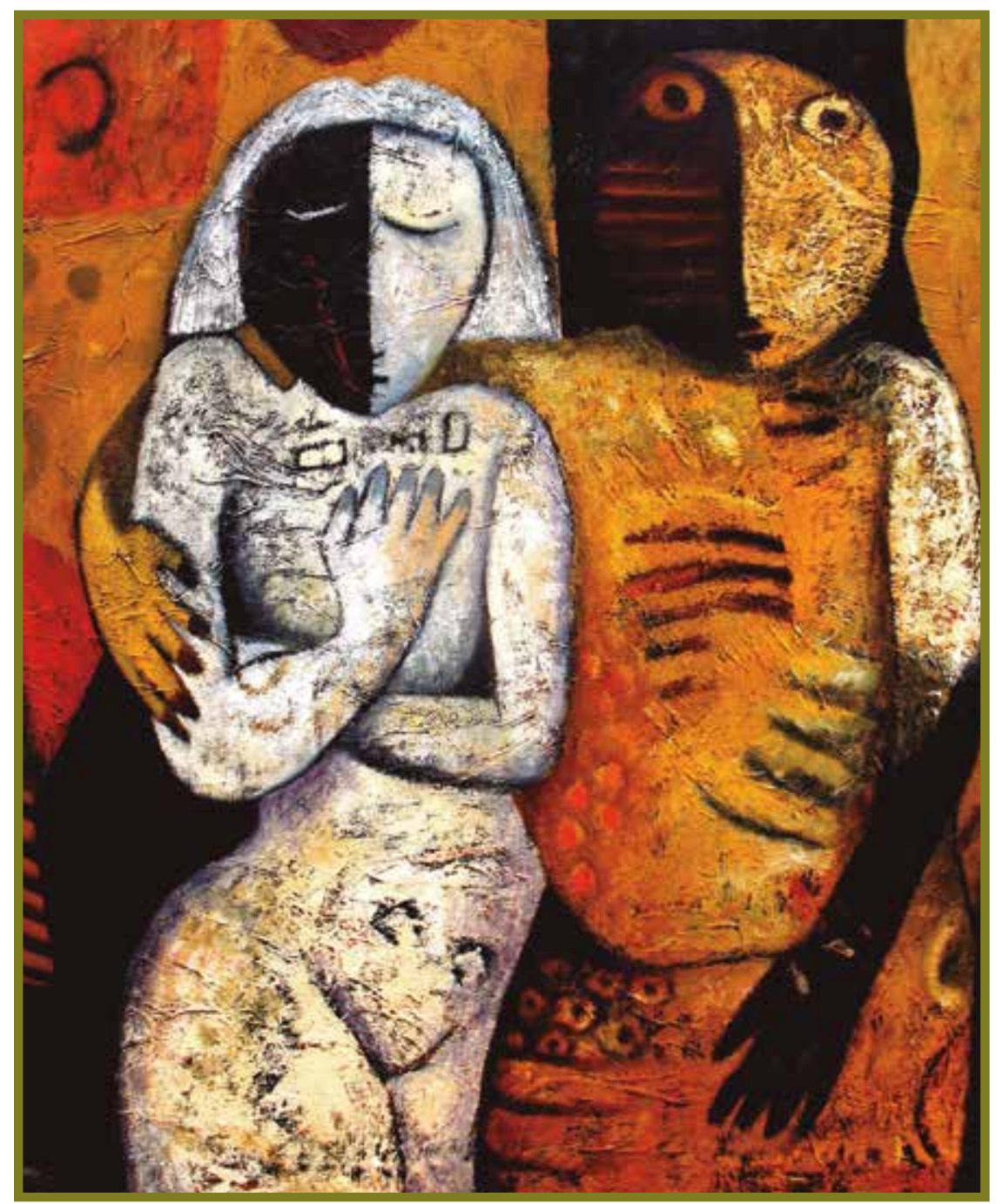

Amándonos. Pintura. Juan Carlos Nananake. 